which mine requires. Both these instruments may be called useful improvements on existing types, but they are in no way a necessity - there are endless others.

Hamorrhage after the operation is usually slight, and if a hæmostatic guillotine is used is practically negligible. Cases in which bleeding persists or recurs are, $I$ think, usually due to a piece of the capsule being left behind and thus preventing athe proper retraction of the vessels into the superior constrictor muscle. I think it is better to remove shreds of the muscle with the tonsil rather than run any risk of leaving any of the capsule behind.

If bleeding is troublesome firm pressure with a gauze plug or marine sponge placed in the sinus tonsillaris will usually stop it. Pressure should be applied from the opposite corner of the mouth and kept up continuously for 15-20 minutes. The ordinary styptics are messy and generally useless. If the bleeding is not controlled by this method, it may be necessary to suture the pillars of the fauces together over a roll of gauze. Michel's clips are useful for this purpose, but require a special instrument for their application. I think it important that before the patient is removed from the operating table the surgeon should inspect the sinus tonsillaris very carefully and see that all bleeding has actually stopped rather than trust to the probability of it so doing.

Ancesthesia is a matter over which much discussion has arisen, and I believe that the advocates of the dissection method still regard very deep chloroform anæsthesia as an important factor in the successful performance of the operation. It is, of course, a help to the operator if the pharyngeal reflex is abolished, and there is apt to be less bleeding, as there are no movements of the pharyngeal muscles to prevent the proper retraction of the torn vessels, but this depth of anæsthesia is to my mind not without its dangers, and personally I do not employ it or regard it as essential. For the guillotine operation ordinary anæsthesia with the chloroform and ether mixture is quite adequate.

I think that it is advisable to give the patient an injection of atropine, 1/120 grain, half an hour before the operation, as this diminishes any shock that may occur. In some case the pharyngeal wall is pulled upon a good deal, and consequently the pharyngeal plexus disturbed. Atropine helps to protect the heart from any reflex vagus impulses that might arise from this cause and affect it adversely.

After-treatment. - The patient should be kept in bed for at least a week. Gargling should not be allowed, as it disturbs the slough which forms over the sinus tonsillaris and increases the liability to bleeding. A simple mouthwash will serve to keep the mouth clean and fresh.

I have no wish to do an injustice to any other operation for enucleation of the tonsils, but, as far as my experience goes, the two that I have described seem to me to be by far the most useful. Enucleation with the blunt guillotine in cases amenable to it and the dissection operation as the sheet anchor.

Harley-street, W.

\section{TREATMEN'T OF CLOTH BY ANTISEPTIC SUBSTANCES IN RELATION TO WOUND INFECTIONS.}

\section{BY MARY DAVIES,}

BACTERIOLOGIST, THE ROBERT WALTON GOELET RESEARCH FUND, HÔPITAL MILITAIRE Y.R. 76 .

THE object of this paper is to suggest the possibility of adopting some means by which clothing may be prevented from becoming a potential factor of infection. The present method of periodical sterilisation of dirty clothing, as practised by some military organisations, can only prove reliably effective in cases where the wearers happen to be wounded before a fresh contamination of their garments can take place.

It is generally conceded that dirty clothing, when carried into a wound by a projectile, becomes a focus of infection. In smears made from fragments of cloth removed at operation, innumerable organisms are seen which correspond in form with those found in the pus taken from any other part of the infected tract. If planted out bodily into culturemedia, these fragments sometimes give rise to a large crop of gas-forming anaerobic bacilli quite different from the aerobic flora revealed in the smears, or grown from swabs passed over the surface of the cloth or from the pus issuing from the wound. In other cases these organisms are already present in full vegetative activity both upon the cloth and throughout the entire area of infection.

Examination of the clothes worn by wounded men returning from the front constantly reveals the presence of sporebearing anaerobes and other bacteria usually found in garden earth. This is particularly the case when the men have been fighting over highly-cultivated districts. It depends upon the nature of the wounds to which the bacteria may be transplanted whether or not they find conditions suitable for their development.

Work has been done in this laboratory by Dr. Kenneth Taylor and myself with a view to ascertaining whether antiseptic substances incorporated with cloth would have any power to inhibit the growth oi bacteria after the cloth so treated had been exposed to the open air for some time before being heavily infected. The antiseptics tested for this purpose included pyxol 5 per cent., formol 5 per cent., tincture of iodine 5 per cent., chinosol $2 \frac{1}{2}$ per cent., sodium fluoride $\mathrm{z} \frac{1}{2}$ per cent., ammonium fluoride $2 \frac{1}{2}$ per cent., thymol saturated solution, and guaiacol saturated solution. The one finally chosen for further experimentation was pyxol (a compound of cresols and soft soap), which has the advantages of being easily procurable, fairly inexpensive, inoffensive as regards odour and colour, and not irritating to the skin even when undergarments saturated in a 5 per cent. solution are worn before the antiseptic has thoroughly dried on them. No great alteration is apparently caused in materials thus treated.

Experiments conducted in vitro.-Experiment 1.-Blue cloth from the uniforms of French soldiers was boiled in dilutions of pyxol ranging from 0.5 per cent. up to 5 per cent., exposed to the weather for one month, and then left uncovered in the laboratory for three weeks. After this length of time the pieces were heavily smeared with a thick emulsion of garden soil containing the spores of $B$. aerogenes capsulatus welchi (perfringens), B. tetani, and other organisms commonly found in wounds. Untreated cloth, smeared with the same mud in like manner, was used as control. After drying for one night at $37^{\circ} \mathrm{C}$. the loose dust was shaken off, and discs measuring $0.5 \mathrm{~cm}$. in diameter were punched out of each specimen. These were pushed into deep melted agar through a sterile glass funnel which was then removed, leaving a disc at the bottom of every tube. The results were as follows :-

Tube 1.-Control (untreated cloth). Cloth pushed half-way up tube by gas ; agar fragmented; gas bubbles issuing from cloth

Tube 2.-Control (untreated cloth). Heavy growth throughout tube and around cloth. No gas.

$$
\begin{aligned}
& \text { Tube 3.-Cloth treated 4\% pyxol (Agar around cloth sterile for } \\
& \text { " 4.- " " } 3 \% ", \quad \begin{array}{l}
0.5 \mathrm{~cm} \text { distance. Occasional } \\
\text { isolated colonies scattered }
\end{array}
\end{aligned}
$$

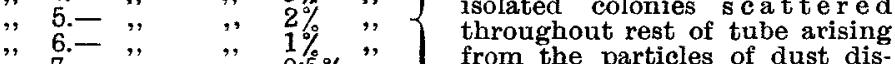

$$
\begin{aligned}
& \text { from the particles of dust dis- }
\end{aligned}
$$

Similar experiments have been frequently made. The results were always consistent. When the above experiment was performed with cloth which had been treated two days before with pyxol 5 per cent., and dried, a zone of at least $1 \mathrm{~cm}$. remained sterile around the disc.

Experiment 2.-Cloth soaked in a 5 per cent. solution of pyxol for 24 hours and aired out of doors for two weeks was tested, the discs being dropped one by one upon a plate of agar still sufficiently soft to allow of their sinking in a little. Emulsions of a 24-hour broth culture of staphylococcus aureus, B. proteus, B. pyocyaneus, and B. aerogenes capsu latus (plate inverted for anaerobiosis) were used, as well as of a mixed culture from garden soil, and pus freshly taken from two cases of badly infected wounds containing streptococcus and other organisms. No growth occurred with the treated discs, except in the case of $B$. pyocyaneus, while in the controls growth took place in each instance. Each of the control discs had an aura of growth around it. B. pyocyaneus appeared to have a partiality for pyxol ; it will grow in 2 c.c. of broth to which 0.5 c.c. of a 1 per cent. dilution has been added.

Bacteria adherent to the surface of cloth previously treated by pyxol, or remaining within the actual zone of its antiseptic influence $(0.5 \mathrm{~cm}$. to $1 \mathrm{~cm}$., according to whether two months or one day had elapsed since it was applied), did not multiply in the agar. The few dislodged in process of implantation were active beyond that sphere. The proportion of organisms remaining upon the cloth was greater than that of those which became separated. There was a remarkable difference as regards growth throughout 
the total length of a tube full of agar according to whether it had been planted with treated or with untreated cloth, though both were equally infected. Agar tubes containing the latter became completely clouded or broken up by gas several hours before isolated colonies appeared in the former, in greater or less number according to the amount of dust dislodged in process of implantation.

Experiments on guinea-pigs.-Experiment 1.-A piece of soldiers' cloth which had been boiled in 4 per cent. pyxol, exposed on the roof for nine days and in the laboratory for two more, together with a piece of untreated cloth for control, were smeared with an emulsion of garden earth (tested for and proved to contain B. aerogenes capsulatus, tetanus and other pathogenic organisms) and tap-water, dried, and a disc $0.5 \mathrm{~cm}$. in diameter punched out of each. Two guinea-pigs were anæsthetised, the skin over the region of the right thigh being shaved, and painted with iodine. An incision was made in the skin and a stab wound in the muscles. One of the treated cloth discs described above was pushed, through a sterile glass tube, deep into the muscle tissue of one pig and one of the untreated discs into the muscle of the other. A few drops of lactic acid were added in order to promote the growth of anaerobic spores. After removal of the tube the wound was closed by strappings. The results were as follows:-

Pig 1-Non-treated cloth (a large strong pig).

24 hours : Wound open, purulent discharge, thigh about twice normal size ; animal apparently sick, but still eating.

48 bours: Wound open, swelling increased, gas and purulent discharge from wound; animal sick refusing food

Killed. Smear from interior of wound infected by numerous forms of bacteria.

Pig. 2-Treated Cloth (a smaller animal).

24 hours: Wound open, slight serous discharge, moderate swelling; animal well

36 hours: Wound closed, swelling less.

48 hours: Thigh approximately normal in size, wound closed. Some induration, but animal apparently well.

Experiment 3.-Cloth steeped in pyxol three days previously and dried, heavily covered with an emulsion of the same earth (this time emulsified by infected pus) and again dried for two days, was brushed and stamped out into dises as before. Untreated cloth was infected in a similar manner.

FIG. 1.

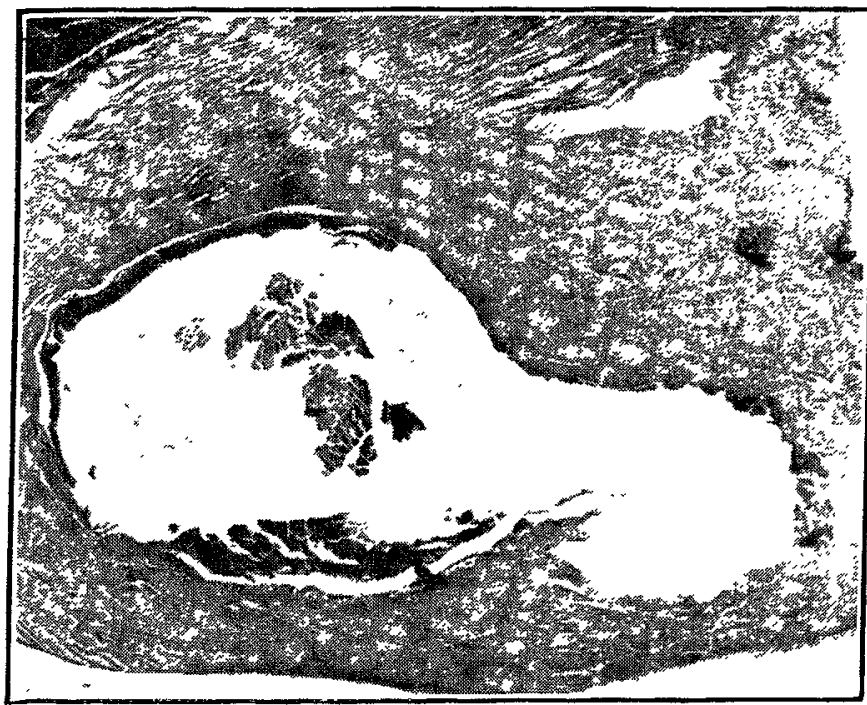

Right thigh. Result following implantation of untreated and infected cloth. $\times 10$

Three pigs were operated, receiving (through the glass tube) a disc of cloth inserted into a stab wound made in the muscles of each thigh. No cut muscle or lactic acid was used in this experiment. The wounds wereclosed by stitches in muscle-sheath and skin as before. The results were as follows :-

$$
\text { Time : } 48 \text { hours. }
$$

Right thighs-untreated cloth.

$P i g \frac{1}{q}$ ) All clean wounds : no dis- $P i g$ 1) All clean wounds ; no dis

Left thighs-treated cloth

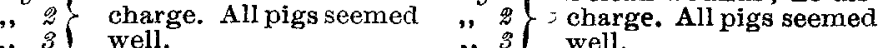
Time : 56 hours.

$P i g$ 1. Leg indurated; wound clean.

".. ," , ; slight purulent discharge.

Pig 1. Leg normal.

3. Leg indurated; wound clean.

,2. ,",

3.

The animals were then killed, legs hardened entire, then dissected, and cloth removed.
Pig 1.-Untreated cloth. Right thigh about three times thickness of left. Cloth firmly embedded. A large abscess involving greater part discolnh filled with white cheesy

$P i g$ 1.-Treated cloth. Left thigh shows cloth tightly enclosed in small cavity. Slight, amount of discolouration immediately around it. (Fig. 2.)

Pig ${ }^{2}$ - Untreated cloth. Right thigh about half as thick again as left. Cloth enclosed in cavity (slightly larger than left), together with a small amount of cheesy material. Cavity connecting with exterior surface of leg. Muscle around cavity discoloured and infiltrated for a leg. Musal

Pig 2. - Treated cloth ; left thigh. Cloth tightly enclosed in very small eavity. Appearance of surrounding tissues normal except for minute abcess a sbort distance from cloth.

Pig 3.-Untreated cloth; right thigh. Cavity a little larger than loth and connecting with exterior. Tissues around infitrated and discoloured for several millimetres. Large abscess on inner side of thigh about $1 \mathrm{~cm}$. diameter, containing white cheesy material. Thigh wice as thick as left.

Pig 3.-Treated cloth ; left thigh. Very small cavity tightly enclosing cloth. Surrounding tissues normal in appearance.

FIG. 2.

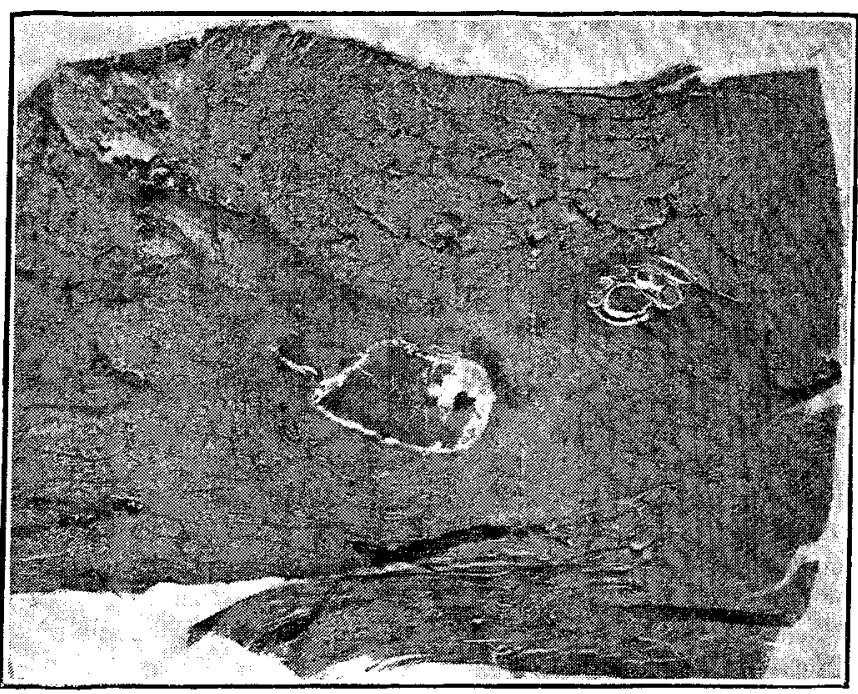

Left thigh. Result following implantation of treated and infected cloth. $\times 10$

Experiment 5.-Whole discs, $0.5 \mathrm{~cm}$. in diameter, of the same infected cloths as those used seven days previously for Experiment 3, were inserted into both thighs of three guineapigs by means of the same technique. The right legs received untreated, and the left legs treated, cloth. A piece of muscle was cut out and reinserted with the disc in the left thighs; this was not done in the case of the right thighs. Time : 1 day.

Right thighs-untreated cloth No pig. 1.-Skin wound closed. Pig 2.-Skin wound closed. Slightly more induration than on left thigh. Pig 3.-Skin wound closed. More induration than on left thigh. Time: 2 days.

Pig 1.-Small amount of swelling. Pig 1.-Normal. Gradual recovery.

Pig 2.-Fxtensive swelling.

Pig 3.-Considerable swelling.

Pig 2.-Apparently normal Time : 5 days.

Pig 8.-Swelling. 3. Apparentily normal

Pig 3. - Symptoms of tetanus. Killed. Pig 3 -Apparently normal Pig 3. - One loop of thick About 1 c.c. of thin pus in muscles. cheesy pus. Smear showed Bacteria numerous in smear-Gram- a few Gram-negative cocel negative bacilli and cocci, Gram- only. positive bacilli, cocci, and diplococci.

Time : 17 days.

Pig 2.-This animal, though appa- Pig 8.-Apparently norma rently in good health, was killed, as in size. On opening the the right thigh was enormously swollen. thigh a small, freely movable Examination showed some sub- tumour the size of a cherry cutaneous cedema. A cystic tumour stone was exposed, and on the size of a small egg was exposed on incision was found to contain inner surface; this contained about thick cheesy pus and the 40 c.c. thin watery pus, which escaped cloth disc. Occasional cocci on incision, leaving the tumour and bacilli.

collapsed. Cloth disc found firmis embedded in muscular wall of cyst.

Results of guinea-pig experiments summarised.-The fact that treated cloth was not found to be absolutely sterile when removed some days after being inserted into a guineapig's leg, but that it was walled off by a very small abscess cavity (causing no external appearance of inflammation) containing a few organisms, seems to suggest that as time 
goes on the antiseptic properties contained in the cloth are absorbed and carried away by the blood, thus allowing the survival of some of the more resistant forms of bacteria. With untreated cloth streptococci and other bacteria (less resistant to the influence of antiseptics although more toxic in their effects) appear to multiply in the wound tissues, causing an extensive inflammatory reaction often affecting the whole limb, with consequent suppuration and induration. The difference between the appearance of the thighs implanted with treated cloth and of those with control cloth was very striking and constant.

It is obvious that the severity of an infection must, to a great extent, depend upon the size of the dose of pathogenic bacteria which is put into the muscles under conditions favourable to their multiplication. It is also logical to suppose that an antiseptic introduced into the same place and at the same time would sensibly diminish the number of individual organisms which could simultaneously awaken into activity. The power of the antiseptic would doubtless decrease by degrees, but as the spores would probably also develop at a proportionately slow rate the body of the animal should have far less difficulty in combating such a gradual infection than if it were suddenly called upon to meet a host of virulent invaders while still suffering from the damage caused by the injury itself.

\section{Conclusions.}

1. It is possible experimentally to prevent cloth from becoming a foous of infeotion in the test tube and in wounds by treating it with an antiseptic before it is contaminated with infected material.

2. Oloth thus prepared remains sufficiently antiseptic to inhibit growth of spores and bacteria (provided these remain attached to it and do not become dislodged), even when it is implanted into culture media favourable to their growth. Some degree of bactericidal value is retained after at least a month's constant exposure to hot sun and storms of rain, and probably for a greater length of time. The antiseptic contained in the cloth diffused into agar to a distance of at least $0.5 \mathrm{~cm}$. from material exposed to the air for seven weeks, preserving a sterile zone around a cloth disc planted into a tube inoculated with bacteria. This suggests that were underclothing also to be treated in the manner described it might, to some extent, lessen the vitality of organisms such as streptococci and staphylococci upon the skin, as the moisture arising from the latter should cause the diffusion of a certain amount of antiseptic.

3. An open wound coming into contact with antiseptic clothing should be less likely to become badly infected, even if both clothes and skin are extremely dirty at the time, than is the case when neither clothes nor skin have any property of inhibiting the growth of the bacteria with which they become saturated in the course of trench fighting.

4. It is also probable that body lice would find the constant diffusion of antiseptic substances inimical to their well-being No experiments have been made in that connexion in this laboratory, but the idea of using antiseptics against vermin is not new.

5. If these deductions are correct, the practice of periodically impregnating the clothing of armies upon active service with an antiseptic would fully repay its cost in reducing the proportion of highly septic wounds. Such a result would be so desirable that if it be possible of attainment no time should be lost in attempting to bring it about. The organisation already in existence for cleaning and sterilising the soiled clothing of troops could probably be used, as the addition of antiseptic to the water in which they are boiled would involve little extra trouble or expense. In view of the fact that pyxol has given the best results in these experiments, it is suggested that antiseptics of the cresol type would be the best to use.

I am deeply indebted to Dr. Kenneth Taylor, who very kindly performed the animal experiments, besides giving me every possible help in the way of supervising and criticising my share of the work, and to Mr. H. E. Magee, who undertook the microscopical sections. My thanks are also due to Dr. Joseph A. Blake for his kindness in reading over and approving of this paper.

Since writing the above further experiments have been made with cloth treated in March last. This was reinfected with pus containing B. aerogenes capsulatus and streptococcus and remained perfectly sterile when reintroduced into culture-media.

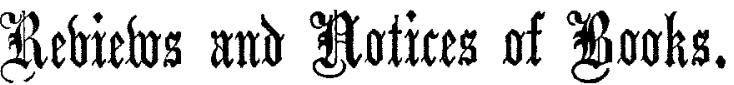

\section{Laboratory Manual in General Bacteriology.}

Prepared by the Laboratory of Bacteriology, Hygiene, and Pathology, Michigan Agricultural College. London: Chapman and Hall. 1916. Pp. 418. Price 10s. 6d. net.

THIs is a schedule of practical work in general bacteriology which is based on the lengthy experience of the teachers of the subject in the Michigan Agricultural College. The work is divided into a series of lessons, each of which affords instruction in some general method or is used to demonstrate some important bacteriological fact or principle. The ground covered is very extensive, and the time occupied by the course must be long. In Part I. general cultural methods and morphology are dealt with, and Part II. is concerned with the physiology of micro-organisms. The applications of bacteriology to the investigation of air, water, sewage, soil, and plants are studied in Part III., which, in addition, treats of the problems of the dairy, the diseases of animals, and the phenomena of immunity. The book is intended to be used in the laboratory, and the actual work to be carried out in each lesson is stated and instructions are given as to the methods to be employed. In addition, there are short explanations of the methods or the theoretical principles which the practical work is intended to teach the stuajent, and appended to most of the lessons are questions as to the deductions which may be drawn or the information which may be obtained from the experiments made. The first part certainly puts the student in possession of all the most important technical methods employed in bacteriology. In the second part the exercises seem well selected to demonstrate the principal facts in the physiology of micro-organisms, especially as to their food requirements and fermentation activities. The practical applications of bacteriology studied cover a wide area and are naturally tinged with the special interests of agriculture. At the end of each lesson references are supplied to text-books or special manuals which illustrate the work done.

Courses of bacteriological instruction are so varied in their aim and so modified by contingent limitations that it is difficult to utilise, as a whole, any scheme which has not been devised for the particular circumstances, but it may be safely predicted that this book will be of considerable service to teachers. The course, to make it suitable for medical students, would require to be shortened in many directions, and expanded somewhat in others. There is a very full bibliography attached, and the book is well printed and illustrated.

\section{LIBRARY TABLE.}

The Healthy Girl. By Mrs. JosepH OUnNING, M.B. Lond., and A. Campbell, B.A. London : Henry Frowde and Hodder and Stoughton. 1916. Pp. 191.-Price 4s. 6d. net.-This book is the product of the experience of a medical director to an open-air school and of a lecturer on hygiene at a technical institution. The authors describe it as an attempt to help the girl who is leaving school to understand herself, and to be of use to mothers and teachers in regard to school life. We think the attempt will succeed. Without anything new and startling to say, the authors contrive to make each subject they deal with of interest and to clothe the dry bones of hygiene with an attractive garb of everyday application. We get much elementary physiology re-stated in simple language, but the chapter on work and rest embodies the results of original observation at Swindon School. Graphs are given showing the fall in weight of girls working for an examination and the rise in weight during the summer holidays. There are wise remarks on concentration. "Working hours should be short, and during that time there should be absolute concentration; if the hours are too long, the girls fall into a habit of half-working in selfdefence, or with an enthusiastic teacher they are overdone.' "An Australian who came over a year or two since was struck by the little work done in so much time." "I have noticed the way in which boys and girls will go on with home lessons all evening in a hot room; they had much better have a real break in the middle." These considerations are strikingly similar to those emerging from the 